\title{
IDENTIFIKASI TUMBUHAN PAKU DI JALUR KAMPUNG EMPAT - KAMPUNG ENAM KOTA TARAKAN
}

\section{Identification of Frond Types, Frond Venation, Sexual Types, and Shape of Spore of Ephypitic Fern at Tarakan, North Kalimantan}

\author{
Fitriania* $^{a}$, Aprianita $^{\mathrm{b}}$ dan Martina S. Tandi ${ }^{\mathrm{b}}$
}

aMahasiwa Program Studi Pendidikan Biologi, Universitas Borneo Tarakan, Tarakan, Kalimantan Utara b Program Studi Pendidikan Biologi, Universitas Borneo Tarakan, Tarakan, Kalimantan Utara

${ }^{*}$ Corresponding author: Jl. Amal Lama, Tarakan Timur, Tarakan, Kalimantan Utara, 77123, Indonesia.E-mail: Fitriani1822@gmail.com

\section{Abstrak}

Tujuan penelitian ini adalah untuk melaksanakan pendataan jenis tumbuhan paku di daerah pemukiman warga di jalur Kampung Empat -Kampung Enam, Tarakan. Tumbuhan paku yang ditemukan sebanyak 11 spesies tumbuhan paku yang terdiri dari 5 famili. Famili terbanyak yang ditemukan adalah Polypodiaceae sebanyak 5 spesies. Kemudian famili terbanyak kedua adalah Lygodiaceae sebanyak 3 spesies. Famili selanjutnya adalah Aspleniaceae, Davalliaceae dan Pteridaceae, yang masing-masing ditemukan 1 spesies.

\section{Kata kunci}

Tumbuhan Paku, Kampung Enam, Kampung Empat

\section{Abstract}

This study aimed to collect data on species of ferns in residential areas in the path of Kampung Empat-Kampung Enam, Tarakan. There were 11 species of ferns found, consisting of 5 families. The most prominent family found was the Polypodiaceae, with five species. Then the second largest family is Lygodiaceae, with three species. The following families are Aspleniaceae, Davalliaceae, and Pteridaceae, each found in 1 species.

\section{Keywords}

Fern, Kampung Enam, Kampung Empat 


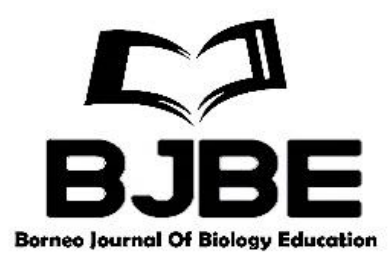

\section{Pendahuluan}

Posisi Tarakan yang berada di Kaimantan Utara merupakan posisi yang dekat dengan garis khatulistiwa. Tarakan memiliki keragaman hayati yang sangat tinggi. Namun, upaya dalam pengidentifikasi masih sangat kurang. Hal ini perlu segera ditindaklanjuti dengan pelaksanaan identifikasi jenis keragaman hayati. Salah satu keragaman hayati yang masih banyak belum teridentifikasi adalah Tumbuhan Paku (Pterydophyta).

Keragaman tumbuhan paku di Indonesia sendiri kurang lebih sebanyak 1.300 jenis telah terdokumentasi (Sandy et al., 2016). Penelitian terkait identifikasi jenis tumbuhan paku di Kota Tarakan beberapa sudah dilakukan di beberapa lokasi, misalnya di Hutan Universitas Borneo Tarakan (Abrori, dan Adhani, 2017).

Beberapa lokasi di luar hutan juga perlu dilakukan, misalkan seperti daerah pemukiman dan daerah yang dekat dengan jalur transportasi. Penelitian ini merupakan langkah awal dalam mengidentifikasi jenis tumbuhan paku di sepanjang jalan dari Lokasi Kampung Empat ke Kampung Enam Kota Tarakan. Pengidenfitikasian di daerah dengan penduduk yang padat dianggap penting karena sebagian besar pengidentifikasian yang telah dilakukan mengarah di daerah Hutan yang identik dengan keragaman floranya.

\section{Material dan metode}

Penelitian ini menggunakan metode jelajah, menelusuri rute jalan besar dari Kampung Empat ke Kampung Enam. Metode dalam penelitian ini adalah metode penelitian deskriptif dengan teknik eksplorasi dan dokumentasi.

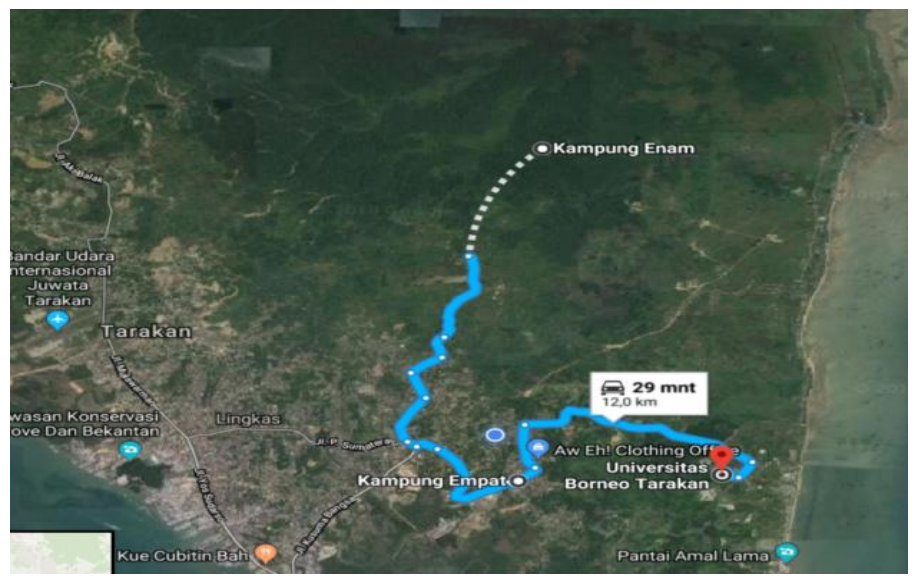

Gambar 1. Lokasi Pengambilan Spesimen Tumbuhan Paku Epifit (Sumber; Google Earth)

Subjek penelitian ini adalah seluruh jenis Tumbuhan paku epifit, yang berada di daerah Kampung Empat - Kampung Enam. Penelitian dilaksanakan pada Sabtu, 19 Mei-24 Mei 2018 


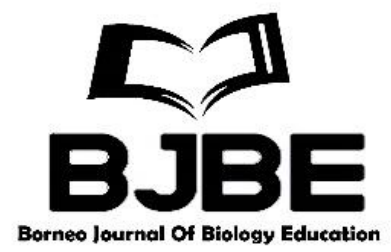

Pengambilan sampel di lakukan dengan cara jelajah, dengan cara mengambil spesimen tumbuhan paku yang memiliki sorus. Langkah selanjutnya peneliti mencatat berapa banyak spesies yang ditemukan pada saat pengambilan data dan mendokumentasikan tumbuhan paku dalam bentuk foto, serta mengawetkan beberapa contoh sampel dalam bentuk herbarium. Tumbuhan paku kemudian diidentifikasi dengan mengacu kepada buku identifikasi seperti Piggot (1988) dan buku identifikasi lainnya.

\section{Hasil dan Diskusi}

Hasil dari identifikasi jenis paku epifit di sepanjang jalan Kampung Empat Kampung Enam Kota Tarakan di dapatkan jenis tumbuhan paku pada Tabel 1.

Tabel 1. Tumbuhan Paku di Jalur Kampung Empat - Kampung Enam, Tarakan

\begin{tabular}{cl}
\hline Famili & \multicolumn{1}{c}{ Spesies } \\
\hline Polypodiaceae & Phymatosorus nigrescens (Bl.) Pic. \\
Polypodiaceae & Drynaria quercifolia J. Sm. \\
Polypodiaceae & Microsorum punctatum Copel. \\
Aspleniaceae & Asplenium nidus L. \\
Davalliaceae & Davallia denticulate (Burm. f.) Kuhn \\
Polypodiaceae & Pyrrosia lanceolata (L.) Farw. \\
Polypodiaceae & Drymoglossum piloselloides (L.) Presl. \\
Pteridaceae & Pteris longifolia L. \\
Lygodiaceae & Lygodium scandens $(\mathrm{L}$.) Sw. \\
Lygodiaceae & Lygodium sp 1 \\
Lygodiaceae & Lygodium sp 2 \\
\hline
\end{tabular}

Berdasarkan hasil yang ditemukan setidaknya terdapat 5 famili tumbuhan paku yang ditemukan pada jalur kampung empat - kampung enam kota Tarakan. Famili tersebut terdiri dari Polypodiacaeae, Aspleniaceae, Davalliaceae, Pteridaceae, dan Lygodiaceae. Famili terbanyak ditemukan adalah Polypodiaceae (5 spesies), dilanjutkn famili Lygodiaceae (3 spesies), serta masing-masing satu spesies pada famili Aspleniaceae, Davalliaceae dan Pteridaceae.

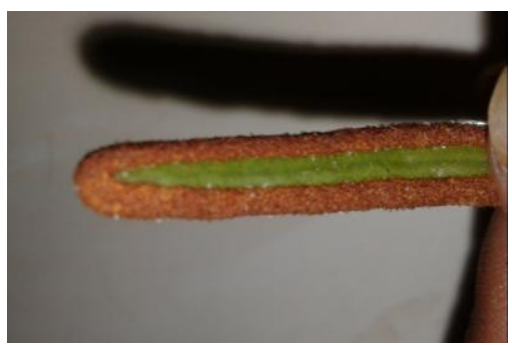

a.

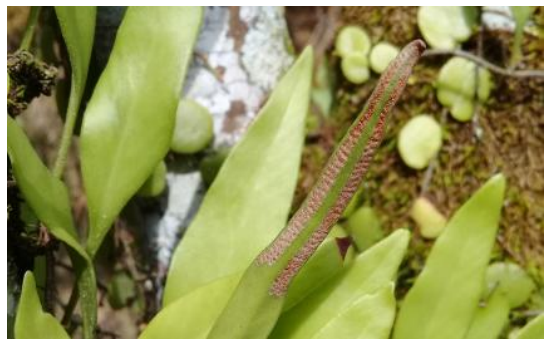

b.

Gambar 1. Contoh spesies famili Polypodiaceae yang ditemukan: a) Drymoglossum piloselloides; b) Pyrrosia lanceolata 


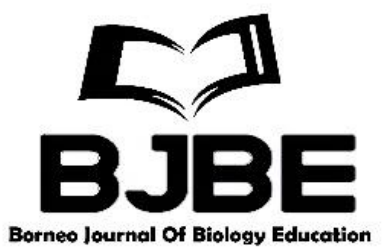

Polypodiaceae sebagai jumlah spesies terbanyak ditemukan pada dasarnya merupakan tumbuhan paku yang memiliki jumlah yang sangat banyak. Berdasarkan data dari Pteridophyte Phylogeny Group I (2016) setidaknya famili ini mencakup 65 genera. Paku ini biasanya merupakan paku epifit, sebagian kecil teresterial (Panigrahi \& Patnaik,1961). Ental umumnya Simple, Pinnatifid, atau bervariasi dari menggarpu (forked) atau pinnate. Rizoma bersisik. Paku ini ditemukan di daerah yang beriklim basah umumnya daerah hutan hujan (Panigrahi \& Patnaik,1961).

Famili selanjutnya yang ditemukan adalah Lygodiaceae. Famili ini hanya memiliki satu genus yaitu Lygodium, atau lebih dikenal dengan pakis panjat dan merupakan tumbuhan asli daerah tropis (Pteridophyte Phylogeny Group I, 2016; Christenhusz \& Chase, 2014). Lygodium memiliki ental yang ramping, fleksibel dan panjang, panjang ental bisa mencapai 12 meter. Ental dapat merambat ke tiang atau kayu (Piggot, 1988). Sorus Lygodium terletak di tepi daun dengan bentuk gerigi memanjang (Kinho, 2009).

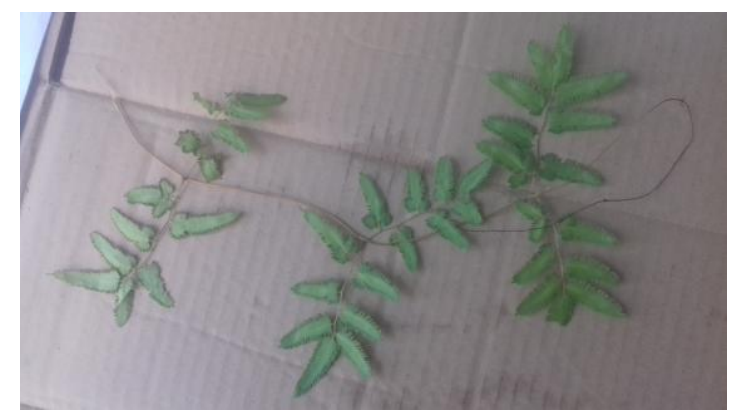

Gambar 2. Contoh Famili Lygodiaceae, Lygodium scandens

Famili selanjutnya adalah Aspleniaceae. Spesies yang ditemukan adalah Asplenium nidus. Biasanya Aspleniaceae memiliki karakter adanya sorus yang memanjang di peruratan daun, biasanya memiliki indusia (Piggot, 1988). Pada Asplenium nidus rimpang membentuk semacam keranjang sehingga ental berkumpul disitu (Rothfels dkk., 2012).

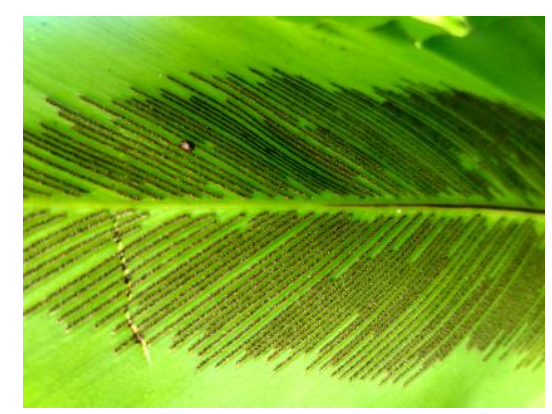

Gambar 3. Contoh Famili Aspleniaceae, Asplenium nidus 


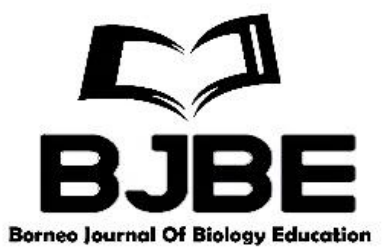

Famili selanjutnya adalah Davalliaceae. Famili ini hanya memiliki satu genus yaitu Davallia (Pteridophyte Phylogeny Group I, 2016). Famili ini berkerabat dekat dengan Polypodiacae dan umumnya memiliki penampakan ental yang sama (Kramer, 1990). Hal yang membedakan adalah bentuk sorus yang menyerupai piala dan dilindungi oleh indusia (Piggot 1988). Spesies pada famili ini merupakkan paku epifit yang memiliki rizoma yang tumbuh menjalar di pohon (Kato \& Tsutsumi, 2008).

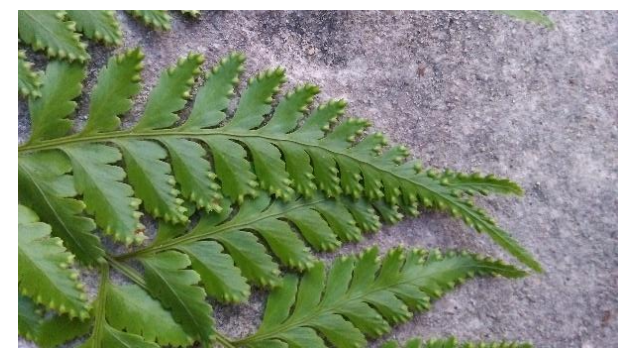

Gambar 4. Contoh Famili Davalliaceae, Davallia denticulate

Famili terakhir yang banyak ditemukan adalah Pteridaceae. Genus yang ditemukan di sepanjang jalur kampung empat - kampung enam adalah Pteris. Genus ini mencakup 300 spesies. Pteris merupakan tumbuhaan native yang tersebar di daerah tropis dan sub tropis di seluruh dunia (Pteridophyte Phylogeny Group I, 2016; Christenhusz \& Chase, 2014). Ciri khas dari pteris adalah pola sorus yang memanjang yang berada di pinggir ental, biasanya memiliki indusial palsu berupa lekukan bagian pinggir ental (Kinho, 2009; Piggot, 1988).

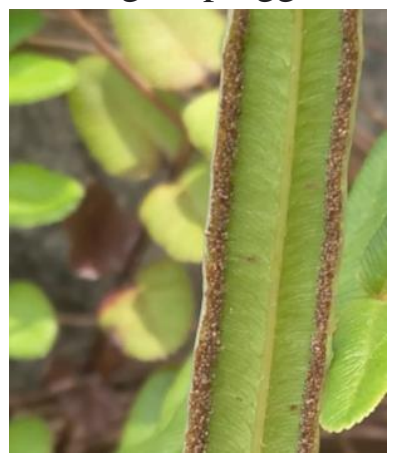

Gambar 5. Contoh Pteridaceae, Pteris longifolia

\section{Kesimpulan}

Dari hasil identifikasi jenis tumbuhan paku disepanjang jalur kampung empatkampung enam Tarakan setidaknya ditemukan 11 spesies tumbuhan paku yang dikelompokkan ke dalam 5 famili. Famili tersebut terdiri dari Polypodiacaeae, Aspleniaceae, Davalliaceae, Pteridaceae, dan Lygodiaceae. Hasil penelitian ini tentu kedepannya akan menyumbangkan terkait data keanekaragaman tumbuhan paku di Tarakan. Penelitian ini juga 


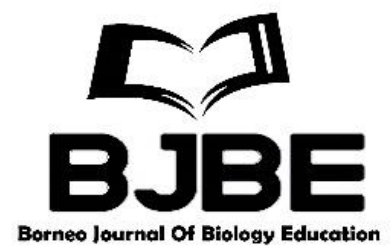

bisa dikembangkan menjadi produk pembelajaran baik untuk pembelajaran biologi di tingkat sekolah menengah atas, ataupun pada perkuliahan taksonomi tumbuhan di pendidikan tinggi.

\section{Daftar Pustaka}

Abrori, F. M., \& Adhani, A. (2017). Developing an atlas based on frond venation patterns analysis of polypodiales in Tarakan. JPBI (Jurnal Pendidikan Biologi Indonesia), 3(3), $222-231$

Abrori, M., \& Adhani, A. (2017). Pengembangan Buku Ajar Berbasis Potensi Lokal Keragaman Tumbuhan Paku di Daerah Tarakan. In Prosiding Seminar Nasional Saling Didik (Vol. 4, pp. 328-332).

Christenhusz, M. J., \& Chase, M. W. (2014). Trends and concepts in fern classification. Annals of botany, 113(4), 571-594.

Kato, M., \& Tsutsumi, C. (2008). Generic classification of Davalliaceae. Acta Phytotaxonomica et Geobotanica, 59(1), 1-14.

Kinho, J. (2009). Mengenal beberapa jenis tumbuhan paku di kawasan hutan payahe Taman Nasional Aketajawe Lolobata Maluku Utara. Manado: Balai Penelitian Kehutanan Manado.

Kramer, K. U. (1990). Davalliaceae. In: Kramer, K. U. \& Green, P. S. (Eds) The families and genera of vascular plants. In: KUBITZKI, K. (Ed) Pteridophytes and gymnosperms, vol. 1, pp. 74-80. Springer-verlag, Berlin, Germany.

Patnaik, S. N., \& Panigrahi, G. (1963). Cytology of some genera of Polypodiaceae in eastern India. II. American Fern Journal, 53(1), 40-46.

Piggott, A. G., \& Piggott, C. J. (1988). Ferns of Malaysia in colour (p. 458). Kuala Lumpur,, Malaysia: Tropical Press.

Pteridophyte Phylogeny Group I (2016). A community-derived classification for extant lycophytes and ferns. Journal of Systematics and Evolution, 54(6), 563-603.

Rothfels, C. J., Larsson, A., Kuo, L. Y., Korall, P., Chiou, W. L., \& Pryer, K. M. (2012). Overcoming deep roots, fast rates, and short internodes to resolve the ancient rapid radiation of eupolypod II ferns. Systematic Biology, 61(3), 490.

Sandy, S. F., Pantiwati, Y., Huda, A. M., \& Latifah, R. (2016). Keanekaragaman Jenis Tumbuhan Paku (Pteridophyta) Di Kawasan Air Terjun Lawean Sendang Kabupaten Tulung Agung. In Seminar Nasional II UM Malang (pp. 828-836). 